\title{
The soluble form of human leukocyte antigen class I antigen causes apoptosis on hepatocellular carcinoma cell lines
}

\author{
TATSUO SHIMURA, TAKETOSHI SUEHIRO, HIDEKI SUZUKI, KOJI OKADA, \\ KENICHIRO ARAKI, TAKAYUKI ASAO and HIROYUKI KUWANO \\ Department of General Surgical Science (Surgery I), Gunma University Graduate \\ School of Medicine, 3-39-22 Showa-machi, Maebashi, Gunma 371-8511, Japan
}

Received July 10, 2006; Accepted September 20, 2006

\begin{abstract}
A soluble form of human leukocyte antigen class I antigen (sHLA-I) has been reported to cause apoptosis on cytotoxic $\mathrm{T}$ cells and inhibit killer activity of natural killer cells via killer-cell inhibitory receptors. However, its effect on cancer cells has not yet been elucidated. We examined the direct effect of sHLA-I on human liver cancer cell lines, HepG2, HLE and HLF. The effects of sHLA-I on cell growth, DNA synthesis, and apoptosis induction were evaluated. To elucidate the mechanisms, cDNA expression arrays were also examined. sHLA-I caused cell growth inhibition, resulting in apoptosis on human hepatocellular carcinoma, dosedependently. In this process, caspase-3 was activated. sHLA-I also inhibited in vivo growth of hepatocellular carcinoma in severe combined immunodeficient mice. sHLA-I caused apoptosis on human hepatocellular carcinoma.
\end{abstract}

\section{Introduction}

Human leukocyte antigen (HLA) class I antigen is a glycoprotein expressed on the cell membrane, which functions in antigen recognition to $\mathrm{CD} 8$-positive cytotoxic $\mathrm{T}$ lymphocyte. A soluble form of HLA class I (sHLA-I) has been identified in various bodily fluids (1-4). Reports indicate that it increases in an immunologically activated status, e.g. in autoimmune diseases, such as systemic lupus erythematosus (5) and rheumatoid arthritis (6), as well as after transplantation (7-10). The liver is considered to be a major organ for producing sHLA-I (11). Peripheral blood lymphocytes (PBLs), especially when activated, are also major producers of these molecules (12).

Zavazava et al have reported that the soluble molecule of HLA class I antigen (sHLA-I) caused apoptosis in primary

Correspondence to: Dr Tatsuo Shimura, Department of General Surgical Science (Surgery I), Gunma University Graduate School of Medicine, 3-39-22 Showa-machi, Maebashi, Gunma 371-8511, Japan E-mail: tshimura@showa.gunma-u.ac.jp

Key words: human leukocyte antigen, hepatocellular carcinoma, apoptosis, soluble form of human leukocyte antigen alloreactive $\mathrm{CD} 8^{+} \mathrm{T}$ cells without a second signal (13). On the other hand, the specific receptor for polymorphic HLA class I antigens, killer-cell inhibitory receptors (KIRs), is expressed on the NK cell, and its signals prevent NK-cellmediated cytotoxicity (14-17). The inhibitory MHC class I receptors may appear on $\mathrm{T}$ cells only after activation, at which point they are needed to control the extent of an immune reaction.

We have investigated the sHLA-I level in patients with virus-induced liver diseases, such as acute hepatitis, chronic hepatitis, liver cirrhosis, and hepatocellular carcinoma (HCC), and in patients with gastric cancer $(18,19)$. The levels of sHLA in patients with liver diseases increased significantly, while those in patients with gastric cancer and HCC were significantly lower than those of normal controls. An increased level of sHLA-I with a liver disorder was considered as a reflection of activated lymphocytes; however, a direct effect of sHLA-I on cancer has not yet been elucidated.

To elucidate this effect, we chose to analyze human liver cancer cell lines, because of the advantages associated with examining the effect of sHLA-I on liver cancer, considering that the liver is assumed to be a major source of circulatory sHLA-I. We examined the direct effect of sHLA-I on the growth of liver cancer cell lines, in vitro and in vivo.

\section{Materials and methods}

Preparation of soluble HLA class I antigen. The purification of soluble HLA class I - B7 antigen was performed using an affinity column, according to a modification of the method reported by Hiraki et al (20). C1R-neo-B7, which was genetically engineered to secrete soluble HLA-B7 antigen, was kindly provided by Professor Carl Grumet, Stanford University. The cell does not have a transmembrane domain in its genetic construction (20). In brief, a culture supernatant of the cell was collected, followed by ultrafiltration with CENTRIPREP (Amicon, Inc., Beverly, MA), which cut the molecule under $10 \mathrm{kDa}$. A W6/32 monoclonal antibody for monomorphic HLA class I was bound to a CNBr-activated Sepharose 4B column (Pharmacia, Tokyo, Japan). The ultrafiltrated supernatant was applied to this column and eluted with $0.1 \mathrm{M}$ glycine- $\mathrm{NaOH}$. After neutralization with $0.1 \mathrm{M}$ glycine- $\mathrm{HCl}$, the eluent was dialyzed with phosphatebuffered saline (PBS). Finally, it was ultrafiltrated with 
CENTRICUT30 (Amicon, Inc.) and used as purified sHLA-I after quantification by an enzyme-linked immunosorbent assay (ELISA) described elsewhere.

SDS-PAGE of purified soluble HLA class I antigen. For evaluation of the purity of the purified SHLA-I, an 8-25\% gradient sodium dodecyl sulphate-polyacrylamide electrophoresis gel was run on a Phast system (Pharmacia) with dithiothreitol (1.5\%; Sigma, Tokyo, Japan) present in the loading buffer. The gel was silver-stained with 2-D silver stain II (Daiichi Pure Chemicals, Co., Ltd., Tokyo). Lowmolecular-weight standards (BioRad, Tokyo), including phosphorylase B $(97.4 \mathrm{kD})$, bovine serum albumin $(66 \mathrm{kD})$, ovalbumin $(45 \mathrm{kD})$, carbonic anhydrase $(31 \mathrm{kD})$, soybean trypsin inhibitor $(21.5 \mathrm{kD})$, and lysozyme (14.4 kD), were run on the gel for sizing.

Growth assay of hepatocellular carcinoma cell line. The liver cancer cell lines, HepG2, HLE and HLF, were provided by the RIKEN cell bank (Tsukuba, Japan). Cell viability was checked by the die-exclusion test using trypan blue. Initially, $7 \mathrm{ml}$ of each cell line, $5 \times 10^{4}$ cells $/ \mathrm{ml}$, was cultivated for 2 days under conditions of $5 \% \mathrm{CO}_{2}$ at $37^{\circ} \mathrm{C}$ in Dulbecco's modified Eagle's medium (DMEM) with $10 \%$ fetal calf serum in a $25-\mathrm{cm}^{2}$ culture flask (Corning, Tokyo) with or without the purified sHLA-I. The concentration of the added sHLA-I was $1 \mu \mathrm{g} / \mathrm{ml}$. As a control, IMDM (Gibco, Tokyo), which was used as a culture medium for C1R-neo-B7, was added at the same concentration as the agent. On the 2nd and 4th day of culture, the cells were removed from the flask using $0.25 \%$ trypsin, and the number of cells was counted. Three sets of cultivation were performed, and the mean value \pm standard error of mean (SEM) of cell counts was analyzed.

DNA synthesis. HepG2 showed highest sensitivity to sHLA-I, so we used this cell line for further examination. Incorporation of $\left[{ }^{3} \mathrm{H}\right]$-thymidine into DNA fraction was measured according to modification of the method reported by Tramontano et al (21). Two $\mathrm{ml}$ of HepG2, $1 \times 10^{4}$ cells $/ \mathrm{ml}$, was cultivated for $48 \mathrm{~h}$ under conditions of $5 \% \mathrm{CO}_{2}$ at $37^{\circ} \mathrm{C}$ in DMEM with $10 \%$ FCS in a 24-well microplate (Corning, Tokyo). Then, 1 or $2 \mu \mathrm{g}$ of the purified sHLA-I, whose concentration had been decided by ELISA, was added. As a control, $2 \mu 1$ of IMDM (Gibco, Tokyo), which was used as a culture medium for C1R-neo-B7, was added. Cells treated with or without sHLA-I were further cultivated for $24 \mathrm{~h}$ after adding $1 \mu \mathrm{Ci} / \mathrm{ml}$ of $\left[{ }^{3} \mathrm{H}\right]$-thymidine (New England Nuclear, Boston, MA); the specific activity was $6.7 \mathrm{Ci} / \mathrm{mmol}$. Cells were then washed twice with ice-cold PBS, followed by two washes with $5 \%$ trichloroacetic acid. The trichloroacetic acid-insoluble material was solublized with a mixture containing $2 \% \mathrm{Na}_{2} \mathrm{CO}_{3}, 0.1 \%$ sodium dodecyl sulfate, and $0.1 \mathrm{~N} \mathrm{NaOH}$. The solution was then transferred to a vial and neutralized with 50\% trichloroacetic acid. Radioactivity was measured in a liquid scintillation counter.

EIA system for the detection of apoptosis. Two $\mathrm{ml}$ of HepG2, $1 \times 10^{4} / \mathrm{ml}$, was cultivated for $48 \mathrm{~h}$ under $5 \%$ of $\mathrm{CO}_{2}$ at $37^{\circ} \mathrm{C}$ in DMEM with $10 \%$ FCS on a 24 -well microplate. Two $\mu \mathrm{g}$ of the purified sHLA-I was added to the plate, and the cells were cultivated for another $6,12,24$, and $48 \mathrm{~h}$. Apoptosis in HepG2 was detected by the modified terminal deoxyribonucleotidyl transferase-mediated deoxyuridine triphosphatebiotin nick end labeling (TUNEL) method (22) using enzyme immunoassay. The culture media and cultivated cells exfoliated using $0.25 \%$ trypsin at the above-mentioned times were collected into a $15-\mathrm{ml}$ tube and centrifuged. After discarding the supernatant, the cell count was adjusted to $1 \times 10^{5}$ cells $/ \mathrm{ml}$ of $70 \%$ ethyl alcohol. When the analysis was finished, $500 \mu 1$ of the cell mixture fixed with ethyl alcohol was added to a culture chamber bottomed with a membrane with a $5-\mu \mathrm{m}$ pore size (Chomotaxicell, Kurabou, Tokyo), topped on a 10-ml tube. To increase the permeability of HepG2, $0.5 \%$ Tween-20 was added and held still at room temperature for $30 \mathrm{~min}$ after washing three times with $0.01 \mathrm{M}$ PBS. One $\mathrm{ml}$ of the reaction mixture: $100 \mathrm{mM}$ sodiumcacodylate, $\mathrm{pH} 7.0 ; 1 \mathrm{mM} \mathrm{CoCl}_{2}$; $50 \mu \mathrm{g} / \mathrm{ml}$ gelatin; $10 \mathrm{nmol} / \mathrm{ml}$ biotin-16-dUTP (BoehlingerManheim Yamanouchi, Tokyo); $100 \mathrm{U} / \mathrm{ml}$ terminal deoxynucleotidyl transferase (Takara Shuzou, Tokyo) was added to the chamber and incubated at $37^{\circ} \mathrm{C}$ for $1 \mathrm{~h}$ under a humidified condition. After washing three times with $0.01 \mathrm{M}$ PBS, 30X streptavidin-alkalinephosphatase was added and incubated for $1 \mathrm{~h}$ at room temperature. After washing with PBS, $100 \mu \mathrm{l}$ of the substrate was added to the chamber, and $100 \mu 1$ of a stop buffer (10\% sodium dodecyl sulphate and $0.05 \%$ EDTA) was added and mixed well. After centrifuging at $3000 \mathrm{rpm}$, the final product was collected into the tube. Half of it was applied to a 96-well microplate, and optical density at $490 \mathrm{~nm}$ was examined using a microplate reader, M-E max (Wako Pure Chemicals, Tokyo). As for the standard curve, HepG2 treated with DNase I (Sigma, St. Louis, MO) at $37^{\circ} \mathrm{C}$ for $1 \mathrm{~h}$ was applied using the same method.

cDNA expression array. HepG2 was cultivated with the purified sHLA-I $(1 \mu \mathrm{g} / \mathrm{ml})$ at $37^{\circ} \mathrm{C}$ for $24 \mathrm{~h}$. HepG2 was also cultivated without sHLA-I as a control. After $24 \mathrm{~h}$ of incubation, attached cells were washed twice with PBS. The attached cells were then scraped from the dish. The total RNA was prepared using a Micro-Fast Track 2.0 kit (Invitrogen, Tokyo). The extracted RNA was applied to Atlas cDNA expression arrays (Clontech, Palo Alto, CA) according to the procedure recommended by the manufacturer. In brief, array-specific $\left.{ }^{[2} \mathrm{P}\right]$-labeled complementary DNA (cDNA) probes were created with reverse transcription. The cDNA probes were hybridized with nylon membranes containing an array of 588 cDNA, and autoradiographs were scanned to identify the patterns of gene expression characteristic of each group. Densitometric analysis was used to standardize the expression of individual genes to a panel of housekeeping controls, and differential gene expression was defined by a signal ratio of at least 2:1.

Western blot analysis. HepG2 was cultivated with the purified sHLA-I $(1 \mu \mathrm{g} / \mathrm{ml})$ at $37^{\circ} \mathrm{C}$ for $24 \mathrm{~h}$. HepG2 was also cultivated without sHLA-I as a control. After $24 \mathrm{~h}$ of incubation, the attached cells were washed twice with PBS containing $100 \mu \mathrm{M}$ sodium orthovanadate and lysed with $0.5 \mathrm{ml}$ of M-PER, mammalian protein extraction reagent (Pierce, Rockford, IL). The protein concentration was measured using the BCA protein assay kit (Pierce). The total cellular protein was 


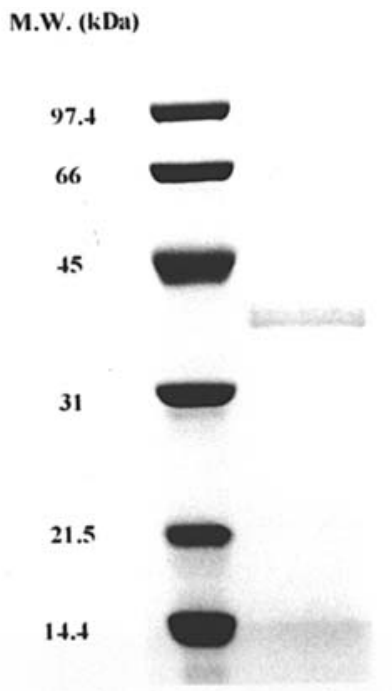

Figure 1. SDS-PAGE of the purified sHLA-I. Bioengineered sHLA-I does not have the transmembrane region. Its molecular weight is $39 \mathrm{kDa}$.

separated in 4-20\% gradient SDS polyacrylamide gel (Daiichi Pure Chemicals, Tokyo) and electroblotted to Hybond-ECL nitrocellulose membranes (Amersham, Tokyo). After being blocked with $5 \%$ non-fat dried milk in PBS containing $0.1 \%$ Tween-20, the membrane was incubated with a mouse antiCPP32 (caspase-3) antibody (Oncogenes Research Products, Cambridge, MA). Immunoblot analysis was carried out using an Amersham ECL immunoblot detection system.

Growth inhibition in vivo. Sub-confluent HepG2 was dispersed by $0.25 \%$ trypsin treatment and suspended in a small volume of DMEM with $5 \%$ of fetal calf serum. After appropriate dilution, $1 \times 10^{5}$ cells were suspended in $1.0 \mathrm{ml}$ of DMEM containing $1 \mu \mathrm{g} / \mathrm{ml}$ of sHLA-I or PBS as a control and incubated at $37^{\circ} \mathrm{C}$ for $1 \mathrm{~h}$. After incubation, $0.1 \mathrm{ml}$ of cell suspension (containing $1 \times 10^{4}$ cells) was directly inoculated into the liver of a severe combined immunodeficient (SCID) mouse (CLEA, Tokyo). The mice were sacrificed 2 weeks after inoculation and evaluated for the presence of hepatic tumors.

Statistics. Statistical analysis of the two groups was carried out using an unpaired-t test. When the $\mathrm{P}$ value was $<0.05$, it was considered to be statistically significant.

\section{Results}

Purity of SHLA-I. Fig. 1 shows the result of SDS-PAGE of sHLA-I run on a gradient gel. The $39-\mathrm{kDa}$ form of sHLA-I is visible. This shows that the sHLA-I found here does not have a transmembrane region, whereas the molecular weight of the membranous type of HLA class I antigen is $43 \mathrm{kDa}$. Breakdown forms of sHLA-I that were smaller than $33 \mathrm{kDa}$ (shown at $\sim 20 \mathrm{kDa}$ ) were eliminated by ultrafiltration. The concentration of sHLA-I was measured and used in the following data.

Growth assay of hepatocellular carcinoma. Fig. 2 shows growth curves of hepatocellular carcinoma cell lines cultivated

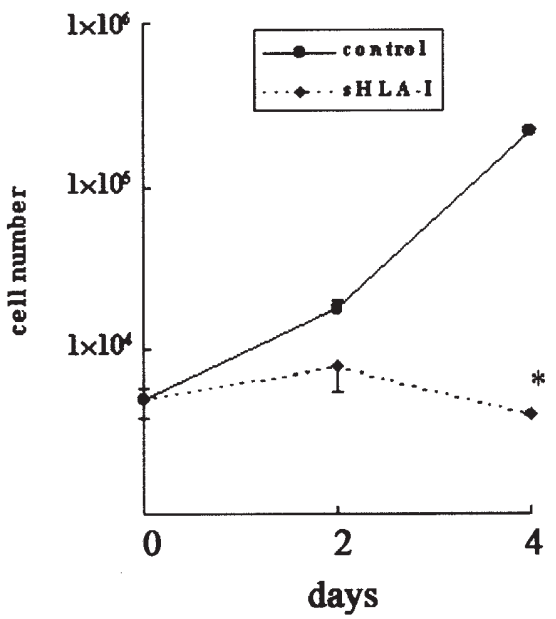

Figure 2. Growth curve of hepatocellular carcinoma cell lines (A, HepG2; B, HLE; C, HLF). The growth of each cell cultivated with sHLA-I was significantly suppressed compared with control $\left({ }^{*} \mathrm{P}<0.05\right)$.

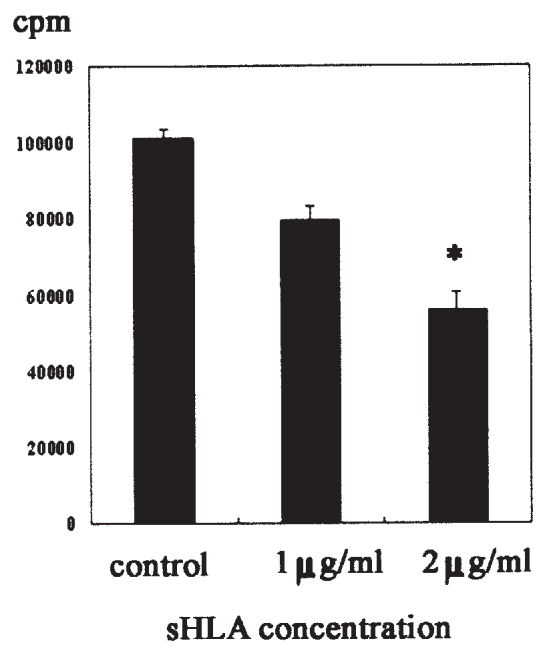

Figure 3. Inhibition of DNA synthesis by soluble form of HLA class I antigen. When HepG2 was cultivated with sHLA-I, $\left[{ }^{3} \mathrm{H}\right]$-thymidine incorporation into HepG2 was significantly inhibited dose-dependently $\left({ }^{*} \mathrm{P}<0.05\right.$, each vs. control).

with or without SHLA-I. The growth of cells when cultivated with sHLA-I was inhibited on days 2 and 4, while cells without sHLA-I grew exponentially. There was statistical significance between the cell count with sHLA-I and that without SHLA-I on the fourth day $(\mathrm{P}<0.05)$. HepG2 showed highest sensitivity to sHLA-I-induced growth inhibition, so we chose this cell line for further examinations.

DNA synthesis. Fig. 3 shows the $\left[{ }^{3} \mathrm{H}\right]$-thymidine incorporation of HepG2 when cultivated with or without sHLA-I administration. HepG2 without sHLA-I showed 1,014,256 $\pm 1,953 \mathrm{cpm}$, while that with $1 \mu \mathrm{g} / \mathrm{ml}$ of sHLA-I showed 79,502 $\pm 3,641 \mathrm{cpm}$ and that with $2 \mu \mathrm{g} / \mathrm{ml}$ of sHLA-I showed 55,582 $\pm 5,208 \mathrm{cpm}$. There was statistical significance between the control and $1 \mu \mathrm{g} /$ $\mathrm{ml}$ of sHLA-I addition $(\mathrm{P}<0.05)$, the control and $2 \mu \mathrm{g} / \mathrm{ml}$ of sHLA-I addition $(\mathrm{P}<0.01)$, and $1 \mu \mathrm{g} / \mathrm{ml}$ of sHLA-I addition and $2 \mu \mathrm{g} / \mathrm{ml}$ of sHLA-I addition $(\mathrm{P}<0.05)$. Thus, sHLA-I inhibited the growth of HepG2 dose-dependently. 

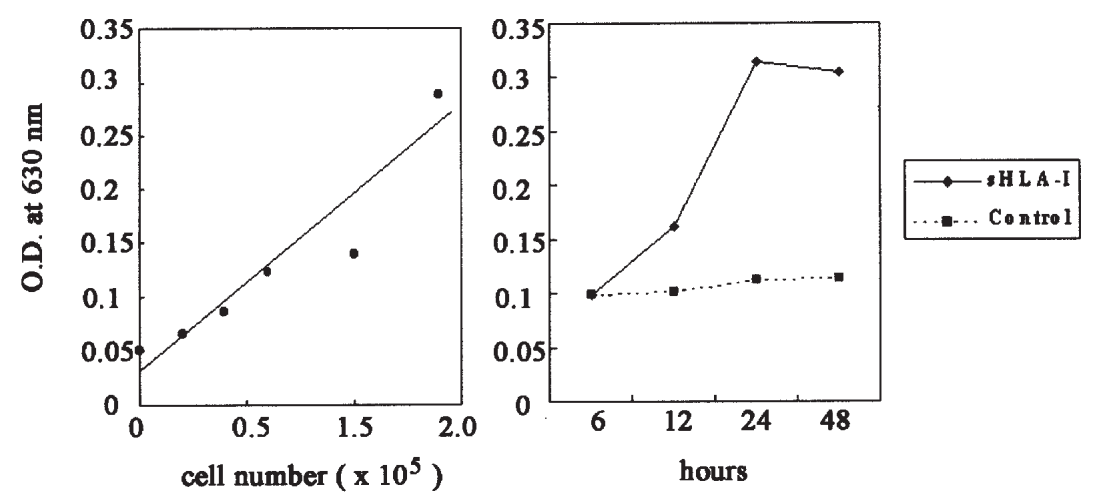

Figure 4. Apoptosis induced by soluble form of HLA class I antigen. Left column shows standard curve when HepG2 was treated with DNase I. Right column shows the result. Apoptosis detected by modified TUNEL method in HepG2 was recognized ( ${ }^{*} \mathrm{P}<0.01$ ). The peak of the reaction was shown $24 \mathrm{~h}$ after sHLA-I addition into the culture medium.

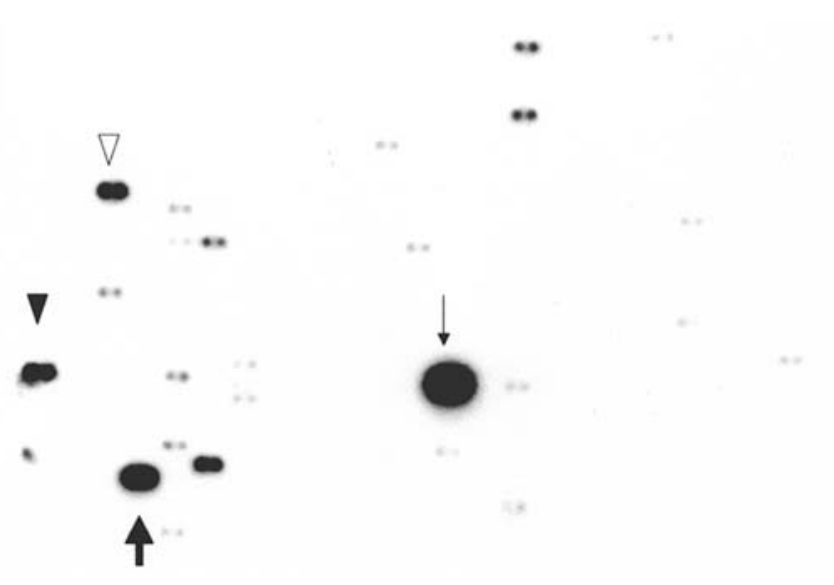

Figure 5. cDNA expression array. Narrow arrow shows $\alpha 1$ catenin, wide arrow shows serine kinase, black arrow head shows tyrosine kinase receptor and blank arrow head shows DCC.

EIA system for apoptosis. Fig. 4 shows the result of EIA for the detection of apoptosis. The left column of Fig. 4 shows the standard curve of this system. The standard curve was obtained by treating cells with DNase as described in the Materials and methods. The result shows that, when SHLA-I was added to the culture medium, HepG2 was led to apoptosis. No apoptosis occurred in the control $(\mathrm{P}<0.05)$.

cDNA expression array. The cDNA expression array showed higher expression of $\alpha 1$ catenin, serine kinase, tyrosine kinase receptor, and DCC precursor (Fig. 5). DCC has been reported to cause $\mathrm{G} 2 / \mathrm{M}$ arrest/apoptosis $(23,24)$, however, there is no significant difference of DCC expression between sHLA-Itreated cells and controls by Western blotting. There are so many kinds of serine kinases and tyrosine kinase receptors that we could not confirm which one is the key molecule in the mechanism of growth inhibition in this study. To elucidate the molecules associated with the mechanism that causes apoptosis on HepG2, we performed Western blot analysis on caspase-3 and CD95 (Fas).

Western blotting. Fig. 6 shows Western blot analysis of caspase-3 (CPP32). In the group treated with sHLA-I, caspase-

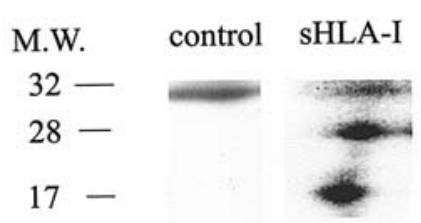

Figure 6. Western blotting for caspase-3. Caspase-3 was activated and broken-down into 28 and $17 \mathrm{kDa}$, when HepG2 was incubated with sHLA-I.

Table I. The result of intrahepatic tumor progression of HepG2 inoculated into SCID mice.

\begin{tabular}{lcc}
\hline & No. of tumor & $\begin{array}{c}\text { Size of tumor } \\
(\mathrm{mm}, \text { mean } \pm \text { SEM })\end{array}$ \\
\hline $\operatorname{sHLA-I}^{\mathrm{a}}(\mathrm{n}=10)$ & 10 & $5.3 \pm 0.9$ \\
$\operatorname{control}^{\mathrm{b}}(\mathrm{n}=10)$ & 0 & 0 \\
\hline
\end{tabular}

${ }^{a}$ HepG2 was suspended in DMEM containing $1 \mu \mathrm{g} / \mathrm{ml}$ of sHLA-I for $1 \mathrm{~h} .{ }^{\mathrm{b}} \mathrm{HepG} 2$ of control group was suspended in DMEM without sHLA-I.

3 showed a breakdown form, which represented an activation of caspase- 3 . In the control group, a band at $32 \mathrm{kDa}$ was shown; however, there was no breakdown form of caspase-3.

Growth inhibition in vivo. Table I shows the result of intrahepatic tumor progression of HepG2 inoculated into SCID mice. HepG2 when incubated with sHLA-I showed no tumor growth, even on microscopic analysis (data not shown), while, in the control group, every mouse had a hepatic tumor at 2 weeks after inoculation. All organs of mice used in this study were examined; however, there was no distant metastasis in either group.

\section{Discussion}

sHLA-I is produced by almost all nucleated cells in the same manner: breakdown, alternative splicing of the transmembrane 
region, etc. (25). The role of an alternative splicing form, $39 \mathrm{kDa}$ in molecular weight, has not yet been elucidated. sHLA-I has been reported to inhibit the killer activity of the NK cell by binding to the KIRs (14-17). It also causes apoptosis on the alloreactive $\mathrm{CD} 8^{+} \mathrm{T}$ cell $(10,13,26-28)$. The levels of sHLA-I in some inflammatory diseases have been reported to be attenuated. Thus, the alternative splicing form excreted outside the cells plays some role in controlling the extent of the immune reaction. Whereas many reports have discussed the relationship between sHLA-I and the immune reaction (5-10), only a few have discussed its biological significance in malignancy $(19,29)$. We have reported that the level of sHLA-I in far-advanced gastric cancer patients was significantly lower than that in a normal control and in the early stages of cancer (19). It is assumed that sHLA-I plays some role in the immune system against tumor cells. Therefore, we estimated that sHLA-I might have a certain direct effect on cancer cells. To assess the direct effect of sHLA-I on the growth of cancer cells, we selected human hepatocellular carcinoma cell lines, because the liver is assumed to be the major producer of sHLA-I.

In the present study, sHLA-I caused the growth inhibition of hepatocellular carcinoma cell lines in a dose-dependent manner. The apoptosis of cytotoxic T cells caused by sHLA-I also occurred without CD95 activation (13). Many pathways have been reported to cause apoptosis. Therefore, we also examined cDNA expression arrays of HepG2 when incubated with sHLA-I. The expression of $\alpha 1$ catenin, serine kinase, tyrosine kinase receptor, and DCC precursor was shown to be higher in the array than in the control; however, we could not confirm which molecule caused this apoptosis.

In chronic liver disease or liver cirrhosis, the sHLA-I level was significantly higher than that of the normal control, but it was lower in HCC than in hepatitis and cirrhosis (18). In patients with chronic hepatitis, recurrence of HCC has been reported to be less frequent than in cirrhotic liver. A more aggressive pre-cancerous state and a longer period of persistent inflammation should cause recurrence of HCC; however, a decreased level of sHLA-I should permit the growth of a hepatocellular carcinoma cell.

Concerning clinical applications, there are some problems to be overcome. sHLA-I has many alleles, as do the membranous HLA class I antigens. Before sHLA-I is injected into a patient, the type of HLA-I should be checked, and a suitable sHLA-I should be produced. If the inhibitory mechanism were more precisely elucidated, we could synthesize a peptide motif that causes the same effect without causing antigenesity. sHLA-I might have an amazing effect on human cancer cell lines, especially on HepG2; therefore, vigorous research should be pursued to elucidate the mechanisms causing growth inhibition and apoptosis by sHLA-I.

\section{Acknowledgements}

The authors wish to thank the RIKEN cell bank (Tsukuba, Japan) for providing the liver cancer cell lines, HepG2, HLE and HLF. The authors also wish to thank Professor Carl Grumet, Stanford University for providing C1R-neo-B7, which was genetically engineered to secrete the soluble HLA-B7 antigen.

\section{References}

1. Charlton RK and Zmijenski CM: Soluble HL-A27 antigen: localization in the $B$-lipoprotein fraction of human serum. Science 170: 636-637, 1970.

2. van Rood JJ, van Leeuwen A and van Santen MC: Anti-HLA2 inhibitor in normal human serum. Nature 226: 366-367, 1970.

3. Riesfeld RA, Allison JP, Ferrone S, Pellegrino MA and Poulik MD: HLA-antigens in serum and urine: isolation, characterization and immunogenetic properties. Transplant Proc 8: 173-178, 1976 .

4. Gelder FB, McDonald JC, Landreneau MD, McMillan RM and Aultman DF: Identification, characterization, and quantitation of soluble HLA antigens in the circulation and peritoneal dialysate of renal patients. Ann Surg 213: 591-597, 1991.

5. Hagihara M, Shimura T, Yamamoto K, Sujirachato K, Tsuji S, Yamamura $\mathrm{M}$ and Tsuji K: Clinical significance of serum soluble HLA class I antigens in systemic lupus erythematosus. Tokai $\mathbf{J}$ Exp Clin Med 18: 61-64, 1993.

6. Weyand CM, Jendro M and Goronzy JJ: Soluble HLA-DR molecules in patients with HLA class II versus class I associated disorders. Autoimmunity 8: 281-287, 1991.

7. Rhynes VK, McDonald JC, Gelder FB, Aultman DF, Hayes JM, McMillan RW and Mancini MC: Soluble HLA class I in the serum of transplant recipients. Ann Surg 217: 485-489, 1993.

8. Shimura T, Hagihara M, Yamamoto K, Takebe K, Munkhbat B and Tsuji K: Quantitation of soluble forms of HLA in kidney transplantation. Transplant Proc 26: 1891, 1994.

9. Grumet FC, Krishnaswamy S, See-Tho K, Filvaroff E and Hiraki DD: Soluble form of an HLA-B7 class I antigen specifically suppresses humoral alloimmunization. Hum Immunol 40: 228-234, 1994.

10. Smith MA, Naziruddin B, Poindexter NJ, Haynes AE, Howard T and Mohanakumar T: Liver transplant recipient sera derived soluble HLA mediates allele specific CTL apoptosis. Transplantation 69: 157-162, 2000

11. Hagihara M, Munkhbat B, Kanai N, Shimura T, Kiuchi T, Inomata Y, Tanaka K, Yamamoto K and Tsuji K: Serum soluble human leucocyte antigen class I in paediatric liver transplantation with live, related donors. Transplant Immunol 5: 219-224, 1997.

12. Brieva JA, Villar LM, Leoro G, Alvarez-Cermeno JC, Roldan E and Gonzalez-Porque P: Soluble HLA class I antigen secretion by normal lymphocytes: relationship with cell activation and effect of interferon-gamma. Clin Exp Immunol 82: 390-395, 1990.

13. Zavazava N and Krönke M: Soluble HLA class I molecules induce apoptosis in alloreactive cytotoxic T lymphocytes. Nature Med 2: 1005-1010, 1996.

14. Lanier LL and Phillips JH: Inhibitory MHC class I receptors on NK cells and T cells. Immunol Today 17: 86-91, 1996.

15. Gumperz JE, Litwin V, Phillips JH, Lanier LL and Parham P: The Bw4 pubic epitope of HLA-B molecules confers reactivity with natural killer cell clones that express NKB1, putative HLA receptor. J Exp Med 181: 1133-1144, 1995.

16. Colonna M and Samaridis J: Cloning of immunoglobulinssuperfamily members associated with HLA-C and HLA-B recognition by human natural killer cells. Science 268: 405-408, 1995.

17. Rajagopalan S, Winter CC, Wagtmann N and Long EO: The Igrelated killer cell inhibitory receptor binds zinc and requires zinc for recognition of HLA-C on target cells. J Immunol 155: 4143-4146, 1995.

18. Shimura T, Tsutsumi S, Hosouchi Y, Kojima T, Kon Y, Yonezu $\mathrm{M}$ and Kuwano $\mathrm{H}$ : Clinical significance of soluble form of HLA class I molecule in Japanese patients with pancreatic cancer. Hum Immunol 62: 615-619, 2001.

19. Shimura T, Hagihara M, Yamamoto K, Takebe K, Munkhbat B, Ogoshi K, Mitomi T, Nagamachi Y and Tsuji K: Quantification of serum-soluble HLA class I antigens in patients with gastric cancer. Hum Immunol 40: 183-186, 1994.

20. Hiraki DD, See-Tho K, Filvaroff E, Krishnaswamy S, de Bello W, Taidi-Laskowski B and Grumet FC: Bioengineered soluble HLA-B7. Genesis, characterization, and occurrence of dimerization. Hum Immunol 40: 235-246, 1994.

21. Tramontano D, Cushing GW, Moses AC and Ingbar SH: Insulin-like growth factor-I stimulates the growth of rat thyroid cells in culture and synergizes the stimulation of DNA synthesis induced by TSH and Graves'-IgG. Endocrinology 119: 940-942, 1986.

22. Gavrieli Y, Sherman Y and Ben-Sasson SA: Identification of programmed cell death in situ via specific labeling of nuclear DNA fragmentation. J Cell Biol 119: 493-501, 1992. 
23. Mehlen P, Rabizadeh S, Snipas SJ, Assa-Munt N, Salvesen GS and Bredesen DE: The DCC gene product induces apoptosis by a mechanism requiring receptor proteolysis. Nature 395: 801-804, 1998.

24. Chen YQ, Hsieh JT, Yao F, Fang B, Pong R, Cipriano SC and Krepulat F: Induction of apoptosis and $\mathrm{G} 2 / \mathrm{M}$ cell cycle arrest by DCC. Oncogene 18: 2747-2754, 1999.

25. Krangel MS: Unusual RNA splicing generates a secreted form of HLA-A2 in a mutagenized B lymphoblastoid cell line. EMBO J 4: 1205-1210, 1985.

26. Spaggiari GM, Contini P, Negrini S, Dondero A, Carosio R, Ghio M, Puppo F, Indiveri F, Zocchi MR and Poggi A: IFNgamma production in human NK cells through the engagement of CD8 by soluble or surface HLA class I molecules. Eur J Immunol 33: 3049-3059, 2003.
27. Contini P, Ghio M, Merlo A, Poggi A, Indiveri F and Puppo F: Apoptosis of antigen-specific T lymphocytes upon the engagement of CD8 by soluble HLA class I molecules is Fas ligand/Fas mediated: evidence for the environment of p561ck, calcium calmodulin kinase II, and Calcium-independent protein kinase $\mathrm{C}$ signaling pathways and for NF-kappaB and NF-AT nuclear translocation. J Immunol 175: 7244-7255, 2005.

28. Poggi A, Contini P, Catellani S, Setti M, Murdaca G and Zocchi MR: Regulation of gammadelta $\mathrm{T}$ cell survival by soluble HLA-I: involvement of CD8 and activating killer Ig-like receptors. Eur J Immunol 35: 2670-2678, 2005.

29. Demaria S, Schwab R, Gottesman SRS and Bushkin Y: Soluble B2-microglobulin-free class I heavy chains are released from the surface of activated and leukemia cells. J Biol Chem 269: 6689-6694, 1994. 